\title{
A primazia do direito comunitário face à supremacia constitucional
}

\section{Community law primacy in view of the constitutional supremacy}

\author{
Marina Pereira Manoel ${ }^{1}$
}

Resumo

A partir do momento em que os países se reúnem com o com vistas a gozar de maior força e espaço no cenário internacional, vislumbra-se a necessidade de uma regra capaz de alçar os interesses do novo bloco. Essa regra, por óbvio, deve salvaguardar o interesse comum do grupo, o qual, não raras vezes, conflita com os interesses concernentes a cada Estado-membro, insertos no ordenamento jurídico nacional. Surge, então, o chamado Direito Comunitário como fonte normativa superior ao direito interno, cuja finalidade é garantir a estabilidade integracionista. Embora alguns Estados-membros tenham hesitado, face ao temor de verem esfacelada a sua soberania, acabou-se por compreender a imprescindibilidade da supremacia do Direito Comunitário para a efetivação de um interesse maior, qual seja, os objetivos e ideais comunitários. Com o Tratado de Lisboa, que veio a corroborar e aperfeiçoar os tratados da União Européia e Comunidade Européia, o bloco passou a ser dotado dos instrumentos necessários para enfrentar os desafios da globalização.

Palavras-chave: Direito Comunitário. Supremacia. Interesse. Bloco. União Européia. Internacional.

\begin{abstract}
From the moment that countries gather in order to be stronger and have more room in the international scenario, it is noticed the necessity of a rule that is able to meet the interests of the new block. This rule, obviously, must assure the group's common interest which, not rarely, conflicts with the interests of each State-member, inserted into the national legal system. The Community law then appears as a ruling source above the internal law, whose purpose is to assure the integrationist stability. Although the State-members have hesitated in face of the fear of having its sovereignty ruined, the importance of the Community law supremacy towards a greater interest, that is, the community purposes and ideals, was finally understood. With the Lisbon Treaty, which corroborated and improved the European Union as well as the European Community treaties, the block was given the instruments necessary for facing globalization challenges.
\end{abstract}

Key words: Community Law. Supremacy. Interest. Block. European Union. International.

1 Advogada e pós-graduanda em Direito Internacional e Econômico pela UEL. 


\section{Introdução}

Este artigo científico elucida como surgiu oDireito Comunitário, qual a influência por ele exercida no campo da integração dos Estados que compõem a União Européia, e também, discute sua incidência sobre o ordenamento interno dos Estados-membros. Preliminarmente, pretende-se explicar, de forma geral, o que é o Direito Comunitário, para revelar sua essência, e os efeitos da aliança entre aqueles entes estatais que contribuíram e contribuem para a sua concretização. Na seqüência, procura-se expor a forma como o Direito Comunitário é aplicado em relação às diretrizes normativas das constituições dos Estados-membros, e se mencionam, como exemplos, alguns países da União Européia que tiveram uma inevitável modificação em suas Constituições. Em seguida, trata-se o recém-assinado Tratado de Lisboa, e discute-se sobre sua importância e seus reflexos no contexto comunitário europeu. Ao final, são trazidas à baila as conseqüências decorrentes da adesão dos Estados-membros ao Direito Comunitário, bem como é debatida a conveniência de uma mitigação do conceito de soberania para um maior alcance dos ideais comunitários.

\section{Direito Comunitário}

No intuito de conceituar o Direito Comunitário, Miguel Ángel Ekmekdjian afirma que:

[...] El derecho comunitário no es un derecho extranjero ni siquiera un derecho exterior, es un derecho próprio de los Estados miembros, tanto como su derecho nacional, com la característica especial de coronar la jerarquía normativa en todos ellos. [...] El ordenamiento jurídico comunitário se configura como un plexo de normas cuyos sujetos activos y pasivos son los Estados miembros y sus cidadanos. Dotado de órganos proprios, tiene poderes soberanos en ciertas materias específicas y - en la misma medida - los Estados miembros han perdido la soberanía en tales ámbitos reservados a al comunidad. En ellos, los países miembros conservan, sin embargo, competencias residuales, pero deben ejercelas conforme a la política legislativa comunitaria [...]. (EKMEKDJIAN, 1996, p. 42).
Feita a elucidação ao conceito de Direito Comunitário, é importante ressaltar que o nascimento da Comunidade Européia por meio do Tratado de Roma (1957), bem como a posterior instituição da União Européia por meio do Tratado de Maastricht (assinado em 1992), culminaram em um processo de integração europeu. Esse processo tornou possível visualizar aos órgãos comunitários, a transferência de poderes e competências, os quais anteriormente, eram considerados parcela inalienável da soberania de seus Estados-membros (GOMES, 2006, p. 63-64).

O conjunto destes tratados constitutivos tem sido considerado a Constituição da Comunidade, pois, conforme salienta Canotilho, são eles que delineiam as diretrizes a serem seguidas, a exemplo da criação de órgãos comunitários, competências, objetivos, limites e até direitos e garantias individuais (CANOTILHO, 1993, p. 902).

Acerca do presente tema, Klaus-Dieter Borchardt assevera que

A Comunidade não só é uma criação do direito como também recorre exclusivamente ao direito na persecução dos seus fins. Por outras palavras, é uma Comunidade 'pelo' direito. É o direito comunitário, não a força do poder, que regula a coexistência econômica e social dos cidadãos dos EstadosMembros. É este direito comunitário que no seu conjunto forma a ordem jurídica comunitária. É a base do sistema institucional. É esse direito que define os processos de decisão das instituições comunitárias e que regula as relações destas entre si (BORCHARDT, 2000, p. 57).

Destarte, para que fossem implementadas as metas traçadas pela Comunidade Européia, era imprescindível a elaboração de regras hábeis a regulamentar os atos instrumentalizadores para a consecução de seus interesses.

Para tanto, nada mais justo que seus membros realizassem uma espécie de "ginástica normativa" para a adequação do direito comunitário aos seus ordenamentos internos, visto que ação política comunitária fundamenta-se em um princípio 
de interesse supranacional, pois as instituições empenham-se na realização dos interesses comunitários.

Contudo, para viabilizar a harmonização das legislações internas dos países componentes dos blocos econômicos, começa a caracterizar-se um direito correspondente a tais relações, o "Direito Comunitário" que possui uma difícil tarefa de compatibilização interna em face das peculiaridades socioeconômicas de cada um dos países membros. Representa o trato dos respectivos Direitos Nacionais, ante a cooperação integracionista de Estados diferentes (SALOMONI, 1999, p. 128).

Nesse sentido, disserta Caiella:

A Constituição, em definitivo, 'constitui'o Estado e o cria como entidade jurídica. Que esta entidade se vê profundamente alterada ao incorporar-se ao processo de integração é coisa evidente. Em primeiro lugar, porque essa alteração é a finalidade imediata da integração, enquanto esta implica em uma redução da soberania, uma redução, ademais, potencialmente indefinida, tanto pela reforma dos Tratados fundacionais como, à margem desta, através da interpretação expansiva das competências que estes Tratados atribuem à comunidade. (CAIELLA, 1999, p. 50, tradução nossa).

Considerando o texto supra, é possível inferir que não há meios de instrumentalizar a Comunidade Européia para a consecução de seus interesses sem que exista uma adaptação de suas diretrizes normativas à ordem constitucional interna de cada um de seus Estados-membros. Esse fato, indubitavelmente, implicará a renúncia de parcela de sua soberania para o alcance do interesse comum, revelando aquilo que se denominou de supranacionalidade.

Ademais, é importante asseverar que a mencionada supranacionalidade, ressaltada no art. $9^{\circ}$ do Tratado de Paris, é instituto basilar do Direito comunitário, já que, conforme destaca Eduardo B. Gomes, ela teve papel relevante na concretização dos “objetivos da União Européia, possibilitando a adoção de políticas comunitárias compatíveis com a legislação dos Estados-membros e uniformidade na tomada de decisões, com base no primado e na aplicabilidade direta das normas comunitárias." (GOMES, 2006, p. 108).

Em suma, a lei fundamental da Comunidade Européia não resulta, necessariamente, em uma constituição, mas em um tratado, cuja estrutura, instituições, objetivos, entre outros, resultam de um acordo que visa à consecução de um fim que beneficie aos interesses de seus membros de uma maneira geral.

De acordo com esse ponto de vista, aqueles que o ratificaram tiveram que proceder à alteração de suas Constituições, razão pela qual se afirmou que, uma vez ratificado o tratado, a lei suprema da Comunidade, e indiretamente de cada Estado a ela vinculado, é esse tratado, não sua Constituição.

Outrossim, é indispensável dispor acerca das fontes do ordenamento jurídico comunitário.

Segundo leciona João Mota de Campos:

O Direito Comunitário tem uma dupla origem: convencional e unilateral. Uma importante parcela das normas comunitárias emerge, com efeito, de convenções concluídas quer no quadro comunitário quer na ordem internacional; outras resultam de actos normativos emanados das Instituições Comunitárias, destinados a assegurar a boa execução ou aplicação dos Tratados que instituíram as Comunidades Européias; mas os princípios gerais do direito e a própria jurisprudência do Tribunal de Justiça das Comunidades Européias assumem no quadro comunitário um especial relevo como fontes de direito. (CAMPOS; CAMPOS, 2004, p. 291).

Portanto, não apenas os tratados compõem o nascedouro do Direito Comunitário, mas inclusive as convenções, os atos normativos, os princípios gerais do direito e a jurisprudência são determinantes da composição desse ordenamento jurídico que irá determinar as diretrizes e bases para a consecução dos objetivos da União Européia. 


\section{Aplicação do Direito Comunitário em face do ordenamento jurídico interno dos Estados- membros da UE}

As relações entre Direito Comunitário e direito nacional geram um quadro em que ambas se completam de forma mútua. $\mathrm{O}$ artigo $10^{\circ}$ do Tratado que instituiu a Comunidade Européia ilustra bem esta relação:

Os Estados-Membros tomarão todas as medidas gerais ou especiais capazes de assegurar o cumprimento das obrigações decorrentes do presente Tratado ou resultantes de atos das instituições da Comunidade. Os Estados-Membros facilitarão à Comunidade o cumprimento da sua missão. Os Estados-Membros abster-se-ão de tomar quaisquer medidas suscetíveis de por em perigo a realização dos objetivos do presente Tratado (SEINTEFUS, 2004, p. 990).

Ora, se há um mútuo compromisso entre os integrantes de colaborarem para que os fins da Comunidade Européia sejam alcançados, por óbvio serão eles incumbidos de não colocarem em risco a concretização das metas comunitárias, mesmo que, para tanto, seja necessário o remanejamento do ordenamento jurídico interno de cada Estadomembro que se confrontar com o que prescreve a ordem comunitária, tendo em vista que ela não tem condições de ser implementada por si própria.

Dessa forma, percebe-se que a Comunidade Européia não é apenas uma comunidade de interesses, mas também uma comunidade solidária.

Por conseguinte, as autoridades nacionais devem não só respeitar aquilo que prescrevem os Tratados comunitários e as normas de execução emanadas das instituições comunitárias, mas, inclusive, aplicá-los e dar-lhes vida.
Contudo, é necessário mencionar que tal integração foi propelida, não simplesmente por razões humanitárias ou sócio-políticas, mas como conseqüência das necessidades de restabelecimento econômico dos Estados-membros e em resposta às novas exigências do capitalismo financeiro. ${ }^{2}$

Conforme salienta Konrad Hesse:

A transformação profunda é inequívoca: o desenvolvimento do Estado, do Estado nacional tradicional, soberano, fechado em si, para o Estado atual, internacionalmente entrelaçado e supranacionalmente atado, encontra sua correspondência na perda da supremacia e do alcance, até agora, de sua Constituição. Como Constituição de um Estado-membro da Comunidade Européia, deve a Constituição respeitar os limites traçados pelo Direito Europeu; seus conteúdos são co-determinados pelos cruzamentos com a ordem comunitária européia. (HESSE, 1998, p. 105-106).

Dessa maneira, tendo em vista a indubitável necessidade dos Estados-membros proceder à adaptação de suas constituições ao Direito Comunitário, passar-se-á, então, à análise de como foi possível o relacionamento deste com o direito nacional de alguns dos distintos Estados, haja vista as peculiaridades de cada qual.

Caso interessante acerca da adaptação do direito interno ao comunitário ocorre com a Constituição da Holanda, que não faz qualquer previsão específica ao processo de integração europeu.

Entretanto, ela tem sido considerada como sendo um dos textos constitucionais que viabilizam ampla margem de atuação ao direito internacional.

É o que se depreende dos artigos 92, 93 e 94 da Constituição Holandesa:

\footnotetext{
$2 \mathrm{O}$ reconhecimento da feição notadamente econômica que marcou o surgimento do Mercado Comum Europeu não pode negligenciar o que Calvo (1998, p. 14), denomina de uma vocação cooperativa decorrente das necessidades advindas das próprias limitações e fracassos das nações européias em garantir os direitos e liberdades fundamentais - possibilitando a consolidação de regimes totalitários - e de assegurar a promoção da paz - ante os inúmeros conflitos armados de que foi palco, visto que o desenvolvimento da Organização da Nações Unidas (1945) e, no âmbito restrito do continente europeu, do Conselho da Europa (1949) concorreu decisivamente para a atual configuração do processo de integração econômico, político, cultural e social europeu.
} 
Art. 92. Poderes legislativo, executivo e judicial podem ser conferidos a instituições internacionais por ou em conformidade com um tratado, estando sujeito, onde necessário, às providências do Artigo 91(3).

Art. 93. Dispositivos de tratados e de resoluções de instituições internacionais, que vinculam todas as pessoas por seus próprios conteúdos, devem entrar em vigor depois de publicados.

Art. 94. Regulamentos estatutários em vigor dentro do Reino não devem ser aplicáveis se sua aplicação entrar em conflito com dispositivos de tratados vigentes ou de resoluções de instituições internacionais. (HOLANDA, 1989). ${ }^{3}$

Portanto, tem-se que no Direito interno holandês é facilmente concretizável a inserção do direito comunitário em seu ordenamento constitucional, já que ele mesmo prevê a não-aplicabilidade de normas que estejam em conflito com os tratados vigentes.

Já a adesão da Áustria à União Européia (1995) implicou em uma expressiva alteração de sua constituição, já que após a sua adesão, a ordem jurídica austríaca passou a estar sujeita não só ao direito constitucional austríaco, mas também ao direito comunitário (dualismo constitucional).

Tal situação vem reforçar ainda mais a tese de que o direito comunitário tem precedência sobre o direito nacional e, também, sobre o direito constitucional federal, ou seja, sobre qualquer ordem jurídica interna daqueles Estados que o compõem (EUROPA, 2007).

Conforme dispõe João Mota de Campos,

As jurisdições nacionais acabaram uma após a outra

- não obstante algumas reservas ou resistências esporádicas que melhor sublinham o consenso geral - por aceitar a superioridade da norma comunitária sobre as disposições internas ordinárias.
Algumas reservas se manifestaram, no entanto, relativamente aa primazia absoluta do direito comunitário sobre certos princípios fundamentais consagrados nas constituições nacionais [...]

[...] o Tribunal Constitucional alemão enuncia toda uma série de proposições que vão muito além da questão específica da garantia dos direitos fundamentais: na realidade o alto Tribunal suscita aí toda a problemática de relações entre o direito constitucional nacional e o direito comunitário, em termos que o levaram a recusar a aceitação da supremacia absoluta do direito comunitário derivado sobre a Lei Fundamental. (CAMPOS; CAMPOS, 2004, p. 403).

Com relação à Alemanha, percebe-se que houve uma contraposição à primazia absoluta do Direito Comunitário, o qual sempre será questionado quando se contrapor a determinados pontos referentes a "direito fundamental garantido em Lei Fundamental”, ou quando se tratar de ofensa à estrutura fundamental da constituição alemã (CAMPOS; CAMPOS, 2004, p. 404).

Portanto, o que se percebe é que a regra é a da primazia do Direito Comunitário, e o que vai restringir sua sobreposição ao Direito interno será o maior ou menor grau de receptividade de seus preceitos pelo ordenamento jurídico interno dos Países-membros. Esse fato ocorre quando a matéria em baila se referir aos direitos fundamentais, como foi elucidado pelo caso da Alemanha.

\section{O Tratado de Lisboa e seus reflexos no Direito Comunitário Europeu}

Um assunto recentemente discutido e cuja relevância para o tema em análise é extraordinária, é o que diz respeito ao Tratado de Lisboa.

\footnotetext{
3 HOLANDA. Netherlands Constitution (1989). 3.6.1999.International Constitutional Law Institute - ICLI:

Endereço Eletrônico: http://www.uni-wuerzburg.de/law/nl__indx.html. Livre tradução da versão inglesa: “Art. 92. Legislative, executive and judicial powers may be conferred on international institutions by or pursuant to a treaty, subject, where necessary, to the provisions or Article 91 (3). Art. 93. Provisions of treaties and of resolutions by international institutions, which may be binding on all persons by virtue of their contents shall become binding after they have been published. Art. 94. Statutory regulations in force within the Kingdom shall not be applicable if such application is in conflict with provisions of treaties that are binding on all persons or of resolutions by international institutions."
} 
O referido tratado tem como um de seus objetivos, o de fazer avançar o projeto europeu, o qual, segundo salientado por José Sócrates, “é um projeto que sempre foi generoso nos propósitos e ambicioso nos objetivos" (SÓCRATES, 2008).

Considerando-se que, nos últimos anos, a instituição encontrava-se limitada em sua capacidade de ação, bem como havia impasses políticos que se revelavam cada vez mais freqüentes no contexto intrabloco, o Tratado de Lisboa revela-se como solução razoável e eficaz.

O referido projeto europeu veio a corroborar a legalidade democrática, o respeito pelos direitos fundamentais, as liberdades comunitárias, a igualdade de oportunidades, a solidariedade, o acesso à justiça, o respeito pelo pluralismo e pela diversidade entre as sociedades européias, axiomas que inspiraram os elaboradores do projeto que consolidou a União Européia.

$\mathrm{Na}$ cerimônia de assinatura do Tratado de Lisboa, ocorrida em 13 de dezembro de 2007, foi reafirmado pelos palestrantes que ele "não elimina nem minimiza as identidades nacionais, nem os interesses específicos dos Estados", mas dispõe de um "quadro de regulação multilateral de que resultam benefícios para o conjunto e para cada uma das partes que nele participam".

Por essa razão, afirmou-se que o projeto da união política e econômica da Europa permanece como fonte de inspiração para outros continentes e como referência para um Mundo carecido de instituições, de princípios e de regras capazes de contribuir para uma regulação à escala global.

Outro ponto que foi reiteradamente elucidado tange à melhoria da eficácia no processo de decisão, quando foi discutido que "só uma Europa capaz de decidir, será uma Europa capaz de obter resultados".

Com efeito, os processos de decisão serão instrumentalizados por uma maioria qualificada, o que aumenta as condições de participação democrática do Parlamento Europeu, reforçando seu papel e salvaguardando a posição central da Comissão Européia e do sistema judicial europeu.

O Tratado de Lisboa, outrossim, define um presidentepermanenteparao ConselhoEuropeu, bem como o Alto Representante para a política externa e de defesa. Além disso, trata da nova composição da Comissão, do reforço da sua legitimidade democrática e do novo sistema de ponderação de votos no Conselho, mudanças que representam um novo equilíbrio entre os Estados e viabilizam um melhor funcionamento das instituições.

Todas essas transformações, portanto, são medidas hábeis e eficazes para garantir à Europa novas condições para afirmar sua voz, sua economia e seus valores.

Portanto, o Tratado de Lisboa tende a reforçar ainda mais a política regional da Europa, pois estabelece como um dos objetivos fundamentais da União Européia a coesão e a solidariedade econômica, social e territorial entre os seus EstadosMembros. Desse modo, não há dúvidas de que a primazia do interesse comunitário revela-se cada vez mais forte e madura.

\section{Efeitos da aplicação do direito comunitário}

Conforme se pode verificar ao longo do presente artigo, o que tem sido objeto de discussão em face da cessão de poderes à Comunidade Européia é se tal fato poderia ensejar a violação da soberania nacional dos Estados-membros.

Ora, é inevitável tratar da relevância atribuída aos Tratados em detrimento da soberania e constituição de cada Estado-membro, já que, quando ratificados, passam a ser inseridos dentro do ordenamento jurídico interno, de tal sorte que seus signatários se vinculam nos termos e condições expressos no instrumento ratificado.

Ademais, é oportuno ressaltar que, como conseqüência da submissão às normas comunitárias, 
surge a sujeição à chamada 'doutrina do efeito direito'. Essa teoria parte da premissa de que apenas os dispositivos legais de direito comunitário claros e auto-aplicáveis deverão englobar o teor do direito interno dos Estados-membros.

Essa doutrina, inclusive, defendia, intrinsecamente, a necessidade de que o direito comunitário tivesse força hierárquica superior ao direito interno dos Estados, primazia que foi salientada em virtude de uma interpretação do Tribunal de Justiça.

O referido órgão jurisdicional manifestou-se no sentido de que, caso as normas comunitárias pudessem ser anuladas por qualquer norma de direito interno, a construção de uma Europa unida estaria comprometida, de tal sorte que se concluiu ser mais acertada a primazia das normas comunitárias em relação ao direito interno dos Estados-membros (CAMPOS; CAMPOS, 2004, p. 368-371).

Nesse diapasão, visto que as normas comunitárias têm efeito direto, à medida que se incorporam de forma imediata ao direito interno, e considerando que elas se revelam de forma hierarquicamente superior ao ordenamento jurídico dos Estados membros, resta reforçar que apesar de ter sido pacificada a sua aplicabilidade em detrimento das Constituições de cada pais integrante da Comunidade Européia. A maioria deles refutou, num primeiro momento, a idéia de delegar funções, outrora privativas e soberanas, a uma entidade de caráter internacional (CARLEZZO, 2002).

Não obstante, revestidos de um ideal maior, qual seja, a criação de uma Europa sem fronteiras, os Estados cederam e procederam a determinadas adaptações em suas respectivas Constituições, dando início (mesmo que paulatinamente), a um processo de delegação de competências, anteriormente internas, a um sujeito externo, como foi o caso da Alemanha, conforme anteriormente esposado (CAMPOS; CAMPOS, 2004, p. 403-404).

\section{Conclusão}

Considerando-se todos os pontos esposados, é possível inferir que, para a real consecução dos ideais comunitários, é imprescindível a formação e reconhecimento do Direito Comunitário como fonte normativa superior ao direito interno. Esse reconhecimento deve restar vivo e solidificado dentro do corpo normativo e social de cada Estado-membro, de tal sorte que reste garantida a estabilidade integracionista.

Não obstante a resistência de alguns Estadosmembros, ao temor de ver esfacelada a sua soberania, acabou-se por compreender a imprescindibilidade da supremacia do Direito Comunitário para a efetivação de um interesse maior, qual seja, os objetivos e ideais comunitários.

Assim, faz-se necessária uma mentalidade coletiva em detrimento de uma visão egoística de seus membros, pois, caso contrário, a integração perderia sua razão de ser.

Como prova disso, foi elaborado o Tratado de Lisboa, instrumento que veio a corroborar e aperfeiçoar os tratados da União Européia e Comunidade Européia, dotando o bloco do quadro jurídico e dos instrumentos necessários para enfrentar os desafios da globalização e responder às expectativas dos cidadãos.

Com isso, é possível vislumbrar a redução dos desequilíbrios sociais, em uma clara demonstração de que o ideal comunitário deve, sim, se sobrepor ao individualismo dos Estados-membros.

Ante todo o exposto, é indiscutível a importância do Direito Comunitário como hierarquicamente superior ao ordenamento jurídico interno, já que, se a integração visa, justamente, a reunião de interesses comuns, nada mais razoável que haja uma maior proteção legal no que tange às finalidades que ensejaram a fundação da Comunidade Européia, pois se encontram voltadas a um denominador comum, e isso facilita a evolução do grupo europeu como um todo. 


\section{Referências}

BORCHARDT, K. O ABC do Direito Comunitário. 5. ed. Luxemburgo: Serviço das Publicações Oficiais das Comunidades Européias, 2000.

CAIELLA, P. Problemas relativos a la compatibilización de los derechos constitucionales y el derecho comunitário. In: SUNDFELD, C. A.; VIEIRA, O. V. (Coord.). Direito Global. São Paulo: Max Limonad, 1999. p. 49.

CALVO, P. Las transformaciones estructurales del Estado-Nación em la Europa comunitária. Nueva Revista de Estudios Políticos, Madrid, n. 99, p. 9-22, 1998.

CAMPOS, J. M.; CAMPOS, J. L. M. Manual de Direito Comunitário. 4. ed. Lisboa: Fundação Calouste Gulbenkian, 2004.

CAnotilho, J. J. G. Direito Constitucional. 6. ed. Coimbra: Livraria Almedina, 1993.

CARLEZZO, E. Soberania $x$ Direito Internacional. 2002. Disponível em: <http://www. escritorioonline.com/webnews/imprime.php?id noticia $=2481 \&$ PHPSESSID $=\&>$. Acesso em: $10 \mathrm{abr}$. 2007.

EKMEKDJIAN, M. Á. Introducción al Derecho Comunitario Latinoamericano. Buenos Aires: Ediciones Depalma, 1996.
EUROPA. Rede Judicial Européia em Matéria Civil e Comercial. Ordem jurídica: Áustria. Disponível em: $<$ ec.europa.eu/civiljustice/legal_order/legal_order_aus pt.htm>. Acesso em: 10 abr. 2007.

GOMES, E. B. Blocos econômicos: solução de controvérsias. 2. ed. Curitiba: Juruá, 2006.

HESSE, K. Elementos de direito constitucional da República Federal da Alemanha. Porto Alegre: SAFE, 1998.

HOLANDA. Netherlands Constitution (1989). 3.6.1999. International Constitutional Law Institute - ICLI. Disponível em: <http://www.uni-wuerzburg.de/law/nl indx.html>. Acesso em: 10 abr. 2007.

SALOMONI, J. L. Reforma del estado y mercosur: hacia la construcción de um derecho público comunitário. In: SUNFELD, C. A.; VIEIRA, O. V. (Coord.). Direito global. São Paulo: Max Limonad, 1999. p.127-156.

SEINTEFUS, R. (Org.). Legislação internacional. Barueri: Manole, 2004.

SÓCRATES, J. Cerimônia de assinatura do Tratado de Lisboa. Disponível em: <http://europa.eu /lisbon_treaty/ glance/index_pt.htm>. Acesso em: 5 fev. 2008. 